\title{
Influence of digital technologies on the formation of social consciousness of students
}

\author{
Irina Vlasova* \\ Don State Technical University, 344002, Rostov-on-Don, Russia
}

\begin{abstract}
The article discusses the possibilities of infocommunications in the educational process, which promote the social consciousness of art specialty students. The analysis of scientific works showed that, despite the intensive development of information technology in higher education, there is an unsystematic use of the emotional sphere of students, which affects the formation of social consciousness. The purpose of the research is to determine the educational potential of digital technologies for the optimal use of new methods in the formation of value orientations and social attitudes of young people while learning to draw. The method of communicative design in the information and educational environment of a university is interpreted as a way of actualizing traditional values that influence the formation of students' social consciousness. In this article we consider the effectiveness of the organizational and pedagogical conditions determined by the objective factors of organizing cooperative social activities in an innovative educational environment. The orientation towards the skills and abilities of innovative critical thinking, combining science and art in the national cultural space are also considered. This contributes to the adaptation of students to professional activities as citizens of Russia and allows them to build their life and professional priorities based on value orientation. The organizational and pedagogical conditions, the method of communicative design of the formation of social consciousness of art department students described in the article can be applied to the process of training specialists in the field of architecture, design, reconstruction, and restoration, as well as painting, graphics, and sculpture.
\end{abstract}

\section{Introduction}

This topic is relevant due to major problems in the digital educational environment. Based on the order of the Ministry of Education of the Russian Federation (of April 17, 2019), this environment is regarded as a set of specially organized pedagogical conditions engaged in the development of personality. In this set, the infrastructural, content-methodological, communicational and organizational components are based on digital technologies. Information technologies in education are considered today as an informational and communicational tool aimed at solving the tasks of the federal project "Digital educational

\footnotetext{
*Corresponding author: iya_tana@mail.ru
} 
environment" within the framework of the national project "Education", "Liberal Arts" and "Science" programs.

Researching the problem of the influence of digital technologies on the formation of the social consciousness of young people, we studied the works of S. Petrell, K. Miller, B. Cooper, D. Rese, D. Maynard. They have been regarding the social priorities in the context of artificial intelligence [1, 2]. We also turned to the works of S. A. Raub, A. Susiliez, S. A. Rahim, who defined teaching strategies based on multiple intelligences used by science and mathematics teachers [3]. And finally, the works of K.L. Thomas, D.K. Cassidy, M.L. Heller also had great value in our study, and especially their research of the impact of students' emotional intelligence and anxiety on academic performance in new information environments [4]. Some other information was taken from the works of K. Luvel, A. Fustan, L. Vershaffel, D. Naurzalina, A. Tolegenov, N. Sadykov [5, 6]. A significant part of Russian research arises the questions of effective teaching of the use of the information space of the Internet [7]. We also noted the conditions of successful self-realization of students in the process of distance learning of visual activity are considered, innovative approaches and technologies in the distance training of bachelor-designers [8, 9]. In some Russian research esarises questions of effective learning of using the information space of the Internet [7]. Noted the conditions of successful self-realization of students in the process of distance learning of visual activity are considered, innovative approaches and technologies in the distance training of bachelor-designers $[8,9]$.

An analytical review of the Russian and foreign authors' works has shown that social priorities in the field of artificial intelligence in the education system of students of creative specialties are not fully disclosed. This determines the research problem: the lack of goalsetting in the formation of value orientations and social attitudes of young people in the context of the intensive development of digital technologies. In this connection, the purpose of the study is to develop a methodological approach to the formation of the social consciousness of students in a digital educational environment. The relevance is determined by the need to analyze the influence of the digital space on the problems of forming the social consciousness of Russian youth, its professional self-determination in the space of traditional culture, directing it into a positive channel of social responsibility.

Standing in the Internet space, which has become a part of daily routine, provides undeniable advantages. For example, instant access to information, use of the communication capabilities of Internet communities, access to many educational platforms, the ability to work remotely, etc. According to Internet World Stats dated December 31, 2020, 5,098,463,772 people are connected to the World Wide Web, and each Internet user spends an average of 6-7 hours a day online. At the same time, there is a certain semantic ambiguity in the Internet space, dependence on the rigid attitudes of various Internet resources; lack of subjective interpretation of information, free access to illegal information, and lack of nonverbal signals that negatively affect the teaching of academic drawing and other art disciplines.

In providing the conditions that make it possible to ensure the formation of orientations and attitudes of students of art specialties, we considered the actual social problems that determine these conditions. "New requirements for educational tasks for the qualification level of university graduates raise a set of problems in the labor market and educational services, the structure and volume of training of specialists, and the professional qualification structure of labor demand, that still unresolved" [10, 236].

The hypothesis of the research is the assumption that one of the conditions for solving the above problems is specially created organizational and pedagogical conditions for the formation of social consciousness of students of art specialties in the digital educational environment of the university. Those actual social problems that determine these conditions must be considered. In this context, we can talk about the structural elements of social 
psychology and ideology, which allow young people to assess reality, molding a certain attitude towards it. This is expressed in feelings, aspirations, goals, and ideals, on which we rely in the process of learning to draw.

To identify the declared organizational and pedagogical conditions for the formation of students' social consciousness, it is necessary to choose an object of cognition that is in the field of fine arts. It is important to consider the "gateways" (the term of G.M. Andreeva), social conditions that ensure the correlation of ideal values with reality, actively use new forms and methods of educational activities, modern Internet technologies for the transfer of knowledge based on the values and traditions of Russian national culture, a school of academic drawing, which is so important for art specialists.

The object of the research is the educational process of preparing students for higher education, considering the stated conditions, relying on the value-oriented function of social psychology. In this context, the assessment by the titular social groups of the phenomenon of public life, their value orientations, based on feelings, aspirations, goals, and national ideals, becomes important.

\section{Materials and methods}

Based on the thesis of the National Project "Education", we investigated the social consciousness of students. In this project, we are talking about the entry of the Russian Federation into the top 10 countries of the world in terms of the quality of general education and upbringing of harmoniously developed and socially responsible people based on the spiritual and moral values of the peoples of the Russian Federation, historical and national cultural traditions. The social consciousness of students is considered as the process of making critical judgments under the influence of the social "irritant" and its influence on the interpersonal interactions and cognitive processes of students in a representative group of students of art specialties (architects, designers, restorers, and urban planners) of the School of Architecture, Design, and Arts of the DSTU. We were based on the opinion of scientists (G.M. Andreeva, L.S. Vygotsky, P. Sorokin), connecting consciousness with experiences, feelings, images, thoughts, expressed with the help of pictorial symbols, in our case - the academic drawing. The English psychologist, a specialist in the problems of psychophysiology, R. Gregory notes that the image of a particular object is fixed in consciousness at the level of sensation. The observer constructs hypotheses about sensory information based on knowledge, experience, and expectations. This kind of construction of hypotheses is related to the creative process and is carried out largely unconsciously [11, p. 6]. A similar idea is put forward by a specialist in cognitive psychology K. Frith, who says that the perception of the world is largely the fruit of fantasy, which, nevertheless, coincides with objectivity, and the human brain manages to combine signals with individual experience [12, p. 111].

To solve the research problems, we determined the principles of the formation of students' social consciousness in the process of learning social phenomena, based on the ideas of the sociologist Pitirim Sorokin:

- only the dominant culture determines what is considered false or true;

- social interactions of people, endowed with certain meanings and values, form certain groups that realize national cultural values;

- the role of social attitudes in the formation of the first impression is considered.

Relying on these principles, we have developed a system of tasks based on basic cultural values and meanings molded by collective ideas about art as a specific social phenomenon. It's important to understand the unity of knowledge and feeling in the becoming of a student's consciousness. This unity is touted as the attitude (feeling) of a person toward the object. As an example, here is the topic of the task: "My hero". 
We considered two different stages of the interaction of students with each other, and a teacher, a group of teachers. Firstly, using the capabilities of the digital educational environment in remote access mode during the Covid-19 pandemic, students performed a specific task - they painted a portrait of a relative who participated in the Great Patriotic War. Considering the special aspects of working in a remote format, the task was complicated by several factors. Students were suggested to use a verbal description (story, novel) about the hero using the popular WhatsApp application, which allows them to instantly exchange voice and video messages.

Secondly, using Internet search platforms such as: Search for War Heroes; Victory Stars; The feat of the people, where the electronic document bank "The feat of the people in the Great Patriotic War of 1941-1945" is presented; Find a soldier; Volunteer project "Archive Battalion"; People's project "Establishing the fate of the missing defenders of the Fatherland"; IIPOD "Immortal Regiment"; The generalized data bank "Memorial", the Immortal Regiment of Russia, "Soldat.ru" - a database of those killed in the Second World War, "Victors" - Soldiers of the Great War and others, students found unique archival information about close relatives - members of their families. The materials obtained using the digital environment were used in solving nonstandard educational tasks when drawing a portrait of a real hero.

At the same time, the digital educational environment was considered as "... a subsystem of the socio-cultural environment, a set of specially organized pedagogical conditions for personality development, in which the infrastructural, contentmethodological, and communication-organizational components function based on digital technologies" [13]. The used Internet resources made it possible to expand the list of known methods and forms of education, having a significant impact not only on the formation of new information culture of students but also in a new way to interpret the signs of communicative interaction between a student and a certain social group in the implementation of artistic cultural values. D. Dutton in his work "Artistic Instinct" notes that art not only gives the most powerful emotional sensations but also allows you to exercise emotions and to construct a certain empathetic situation [14, p. 6].

Standard educational tasks using information technologies in teaching allow building a pedagogical process aimed at the formation of the social identity of the younger generation, united by common goals tasks, a common emotional field, which forms the social consciousness of students of art specialties.

Thirdly, it is necessary to analyze and compare the information obtained to continue the study. The task of visual analysis of photographic materials from the life history of the Hero of the war years and the present was set, which made it possible to solve the research, analytical, psychological, educational, aesthetic, compositional, and visual tasks of creating an artistic image at the level of apperception, i.e., the highest level of consciousness of the author of the drawing.

\section{Results}

We conducted several diagnostic procedures using digital technologies (testing, questioning, frequency analysis, Pearson's correlation analysis) based on primary associations, artistic images, and social schemes using digital technologies.

We have identified the relationship between the level of motivation and value orientations. For this, we carried out a Pearson correlation analysis (Table 1, Figure 1).

Table 1. Correlation analysis of the relationship between the level of motivation and value orientations 


\begin{tabular}{|l|l|}
\hline 13 cultural monuments &, $235\left(^{*}\right)$ \\
\hline 14 material prosperity &, $228\left(^{*}\right)$ \\
\hline 16 joy of life &, $436\left(^{* *}\right)$ \\
\hline 18 responsibility &,$- 316\left(^{* *}\right)$ \\
\hline 20 independence &, $410\left(^{* *}\right)$ \\
\hline 21 diligence &, $286\left(^{* *}\right)$ \\
\hline 22 preservation of national heritage &,$- 247\left(^{*}\right)$ \\
\hline
\end{tabular}

We examined the relationship between the level of aspirations and value orientations. Correlation analysis of Pearson was carried out. The data obtained are presented graphically using the correlation pleiade (Figure 1).

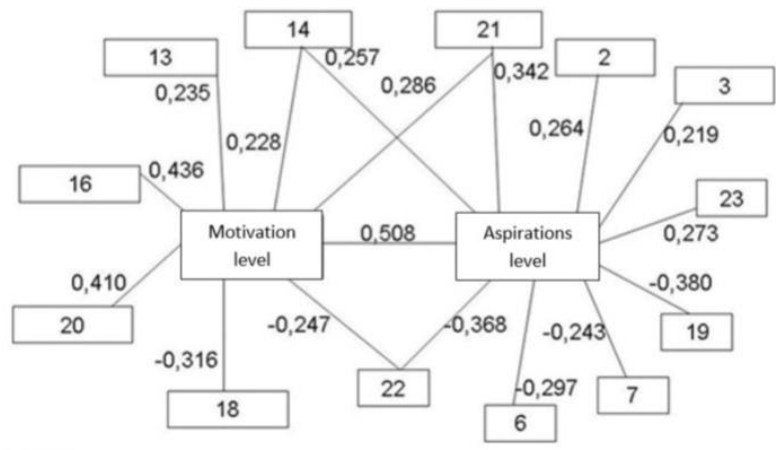

Fig. 1. Correlation pleiade of dependence of the level of motivation, the level of aspiration and value orientations: 2 - health; 3 - national culture; 6 - folk traditions; 7 - happy family life; 13 - cultural monuments; 14 - material prosperity; 16 - joy of life; 18 - responsibility; 19 - competence; 20 independence; 21 - diligence; 22 - preservation of the national heritage; 23 - internet

Correlation analysis of the relationship between the level of motivation, the level of aspirations and value orientations is shown in Table 2 .

Table 2. Correlation analysis of the relationship between the level of motivation, the level of aspirations, and value orientations

\begin{tabular}{|c|c|c|}
\hline & Motivation & Aspirations \\
\hline Motivation & 1 &, $508\left(^{* *}\right)$ \\
\hline Aspirations & $.508\left(^{* *}\right)$ & 1 \\
\hline 1 active deedful life & -0.097 & 0.101 \\
\hline 2 health & 0.031 & $.264\left(^{*}\right)$ \\
\hline 3 national culture & -0.003 & $.219\left(^{*}\right)$ \\
\hline 4 love & 0.027 & -.006 \\
\hline 5 developement & -0.102 & -.157 \\
\hline 6 folk traditions & -0.163 & $-.297\left(^{*}\right)$ \\
\hline 7 happy family life & -0.141 & $-.243\left(^{*}\right)$ \\
\hline 8 creation & 0.134 & -0.045 \\
\hline 9 national identity & 0.036 & -0.021 \\
\hline 10 learning & -0.145 & -0.103 \\
\hline 11 interesting job & -0.182 & -0.087 \\
\hline 12 folk art & -0.18 & -0.185 \\
\hline 13 cultural monuments & $.235\left(^{*}\right)$ & 0.132 \\
\hline 14 material prosperity & $.228\left(^{*}\right)$ & $.257\left(^{*}\right)$ \\
\hline 15 high aspirations & 0.194 & 0.125 \\
\hline
\end{tabular}




\begin{tabular}{|l|l|l|}
\hline 16 joy of life & $.436\left(^{* *}\right)$ & 0.183 \\
\hline 17 education & -0.12 & -0.082 \\
\hline 18 responsibility & $-.316\left(^{* *}\right)$ & -0.139 \\
\hline 19 competence & -0.173 & $-.380\left(^{* *}\right)$ \\
\hline 20 independence & $.410\left(^{* *}\right)$ & 0.023 \\
\hline 21 diligence & $.286\left(^{* *}\right)$ & $.342\left(^{* *}\right)$ \\
\hline $\begin{array}{l}22 \text { preservation of the } \\
\text { national heritage }\end{array}$ & $-.247\left(^{*}\right)$ & $-.368\left(^{* *}\right)$ \\
\hline 23 internet & 0.148 & $.273\left(^{*}\right)$ \\
\hline 24 spirituality & -0.117 & 0.141 \\
\hline 25 beauty & 0.125 & 0.074 \\
\hline
\end{tabular}

Note. ${ }^{* *} \mathrm{p}=0.01 ; * \mathrm{p}=0,05$

We found that students form their judgments based on stable value orientations and attitudes; the process of understanding is considered as identification with others; reflection, as awareness of oneself as others; social consciousness as a reasonable organization of joint social activities.

After solving the problem and pin-pointing the purpose of the study, we are going to present theoretical conclusions and results.

- A digital educational environment using signs of communicative interaction, in the form of a graphic semiotic system, forms a new information culture of students, social responsibility, social consciousness;

- Organizational and pedagogical conditions have been substantiated as a system of subjective and objective factors of the learning process in an innovative educational environment. This educational environment allows students to adapt to the professional activity and build their life and professional strategies, considering value orientations, cultural and social identity [15].

- In the process of forming students' social consciousness, we used a method of communicative projection presented by N.F. Fedorov. This method is also known as a method of active learning. In the works of N.F. Fedorov, M.S. Kagan, any idea is considered as a design hypothesis that can be tested during its practical realization. We have also considered the specifics of the creative process in the digital environment during the process of working on a given task. We consider it as a complicated system of semiotic interactions in the specified social group.

- The phenomenon of "co-knowledge", which expresses the emotions (experiences) of students, is considered as "a system of relations with the world: attitude to things, attitude to other people, attitude to oneself (S. L. Rubinstein, V. N. Myasishchev, E. V. Ilyenkov). These interrelationships allow us, following scientists, to distinguish cognitive, emotional and active (behavioral) relations that form components of the integral structure of the personality's attitude and are reflected in acts of consciousness" (N. I. Sardzhveladze).

- The formation of the social consciousness of students occurs in the process of creative artistic activity, which involves:

- orientation to the psychological mechanisms of consciousness formation: cognitive component, emotional (affective component), active attitude to the world (conative component), to oneself, to society;

- artistic and aesthetic perception of cultural values as a type of co-creation, presupposes emotional empathy associated with responsiveness to a word, image, color, line, shape, design, etc.

- orientation to socially significant events, national values and meanings;

- prompt exchange of information using Internet resources (subject-object relations); 
- presentation of results on the Internet;

- socially-oriented activities (exhibitions, socially-oriented master classes, volunteer work of students, etc.).

\section{Discussion}

The significance of this work is to identify the psychological characteristics, patterns of the formation of social consciousness of students in specially created conditions. Organizational and pedagogical conditions for the formation of social consciousness of students of art specialties represent an emotionally creative environment - the communicative field of subject-object interaction in their cause-and-effect relations: meaningful, procedural and target-related.

When forming the social consciousness of students, we have used the method of communicative design in the information and educational environment as a method of active cognition. At the same time, artistic design activity as a set of mechanisms for solving a design problem was considered as a system of operations which are isomorphic to the process of thinking. This allows to organize the process of communicative design in a search form. Using information from various environments and adapting it to the designing tasks of academic drawing, students, with the possession of digital technologies, master the complex tasks of the artistic and aesthetic organization of the spatial (air) environment, the construction of the visual plane, using instrumental, communicative, symbolic means of expression.

At this stage, the methodological approach to the formation of social consciousness of students in a digital educational environment was focused on motivation aimed at the social behavior of the student, working with artistic images, building an algorithm for the practical action of solving the problem.

Now we present the psychological mechanics related to forming of the social consciousness:

- cognitive component (system of knowledge, skills, self-reflection of project activities); focus on value relationships, expressed in the design results that form the quality level of professional activity;

- emotional (affective) component (attitude) manifests itself in the system of communication relations; presupposes a developed emotional-volitional sphere of personality, understanding of one's place in society, in the system of artistic culture;

- conative (behavioral) component (artistic design activity). The ability to find logicalstructural connections between the image, morphology of objects, and human life; manifests itself in self-realization in creative activity, the ability to independently solve non-standard tasks.

Thus, as a result, an author's drawing is created, endowed with unique properties: the completeness of the artistic image, new socially significant qualities and values when solving such a complex topic, performing skills, the correspondence of the artistic form to its content.

\section{Conclusions}

Summing up the results of the research, it should be noted that the inclusion of students in the value-semantic field of artistic activity made it possible to focus on the cultural meanings of the traditional academic school of drawing. In the process of artistic and design activities, a need for creativity is formed. Its boundaries are expanded and transferred to other activities. The method of communicative design in the informational 
and educational environment of the university contributed to the formation of students' value orientations and social attitudes, a set of qualities that are a factor of successful socialization and professionalization.

The problem we raised presupposes further scientific reflection on the identified issues, including the issues of the influence of digital technologies on the unconscious processes, which are reflected in artistic activity. Fostering patriotic feelings of youth through the development of mechanisms that provide a new methodological and methodological toolkit for influencing the consciousness of youth by means of the fine arts. Comprehensive support of young talented architects, designers, restorers promoting Russian national traditions in their professional activities; respect for the national cultural heritage, its positioning by means of art, and emphasis on the individual characteristics of the teacher: professionalism, high culture, national interests, patriotism.

\section{References}

1. S. Petrella, C. Miller, B. Cooper, Orbis 65 (1), 75-100 (2021). doi: 10.1016/j.orbis.2020.11.004

2. G. Resce, D. Maynard, Technological Forecasting and Social Change 137, 61-75 (2018). doi: 10.1016/j.techfore.2018.06.044

3. S. Tajularipin, A.R. Abdurahman S.S.A. Rahim, Procedia - Social and Behavioral Sciences 8, 512-518 (2010). doi: 10.1016/j.sbspro.2010.12.070

4. L.C. Thomas, J.C. Cassady, M.L. Heller, Learning and Individual Differences 55, 4048 (2017). doi: 10.1016/j.lindif.2017.03.001

5. K. Luwel, A. Foustana, Y. Papadatos, L. Verschaffel, Journal of Experimental Child Psychology 108 (1), 61-76 (2011). doi: 10.1016/j.jecp.2010.06.001

6. D. Naurzalina, A. Tolegenova, A. Karabalina, B. Almurzayeva, S. Bakiyeva, N. Procedia - Social and Behavioral Sciences 171, 390-395 (2015). doi: 10.1016/j.sbspro.2015.01.137

7. A.A. Yakovleva, E.O. Niedergaus, Influence of the digital educational environment on the formation of features of consciousness of modern youth, XXII Ural Sociological Readings. National projects and social and economic development of the Ural region. Proceedings of the All-Russian scientific and practical conference, pp. 322-326. Ural University Publishing House, Ekaterinburg (2020).

8. N. Zakharova, I. Vlasova, O. Kartavtseva, Technologies of tutorial assistance in the visual activity distance education for the bachelors-designers, Innovative Technologies in Science and Education (ITSE-2020), E3S Web of Conferences 210 22014, (2020).

9. N.Yu. Zakharova, I.M. Vlasova, I.V. Protopopova, R.L. Lukyanov, IOP Conference Series: Materials Science and Engineering 698 (3) 033013, (2019).

10. M.S. Perminova, Regional features of the educational services market in modern Russia, PhD Thesis, (Saratov, 2010).

11. R. Gregory, Seeing Through illusions (Oxford University Press, New York, 2009).

12. C. Frith, Making Up the Mind: How the Brain Creates Our Mental Word (Blackwell Publishing, Oxford, 2007).

13. Order of the Ministry of Education of the Russian Federation of April 17, 2019. No. 179 "On approval of methods for calculating target indicators of federal projects of the national project "Education". URL: https://legalacts.ru/doc/prikaz-minprosveshchenijarossii-ot-17042019-n-179-ob-utverzhdenii/. 
14. D. Dutton, The Art Instinct: Beauty, Pleasure, and Human Evolution (Bloomsbury Press, New York, 2009).

15. I.M. Vlasova, Formation of professional competence of design students using universal methods of archetypal iso constructions, PhD Thesis, (Moscow, 2018). 